\title{
Evaluation of microleakage of class II dental composite resin restorations cured with LED or QTH dental curing light; Blind, Cluster Randomized, In vitro cross sectional study
}

Faramarz Zakavi ${ }^{1}$, Leila Golpasand Hagh², Soheila Sadeghian ${ }^{3}$, Virginia Freckelton ${ }^{4}$, Arash Daraeighadikolaei ${ }^{1 *}$, Elham Ghanatir ${ }^{1}$ and Najmeh Zarnaghash ${ }^{1}$

\begin{abstract}
Background: The aim of this study is to compare the microleakage of Class II dental composite resin restorations which have been cured by three different LED (light emitting diode) light curing modes compared to control samples cured by QTH (quartz tungsten halogen) light curing units (LCUs), to determine the most effective light curing unit and mode of curing.

Results: In this experimental study, class II cavities were prepared on 100 sound human premolars which have been extracted for orthodontic treatment. The teeth were randomly divided into four groups; three experimental and one control group of 25 teeth each. Experimental groups were cured by either conventional, pulse-delay, or ramped curing modes of LED. The control group was cured for 20 seconds by QTH. The restorations were thermocycled (1000 times, between 5 and $55^{\circ} \mathrm{C}$, for 5 seconds dwell time), dyed, sectioned mesio-distally and viewed under stereo-microscope (40x) magnification. Teeth were then scored on a 0 to 4 scale based on the amount of microleakage. The data were analyzed by Chi-square test.

No significant difference was demonstrated between the different LCUs (light curing units), or modes of curing, at the enamel side $(p>0.05)$. At the dentin side, all modes of LED curing could significantly reduce microleakage $(p<0.05)$. The results suggest that slow start curing improves marginal integrity and seal. High intense curing endangers those aims.

Conclusions: Comparison between the three LED mode cured composite resin restorations and QTH curing showed LED curing in all modes is more effective than QTH for reducing microleakage. Both LED and QTH almost completely eliminate the microleakage on the enamel side, however none of them absolutely eliminated microleakage on the dentin side.
\end{abstract}

Keywords: Class II cavity, Composite restoration, Microleakage, LED, QTH

\section{Background}

Resin-based composites are synthetic resins which are used in dentistry for tooth restoration, or as an adhesive. There are two types of tooth colored restorative materials; self-cured and light-cured resins. The difference between them is the start polymerization, or how curing

\footnotetext{
* Correspondence: adaraei@pacific.edu

'Department of Operative and Esthetic Dentistry, Ahvaz Jundishapur Dental School, Ahvaz Jundishapur University of Medical Sciences, Ahvaz 6135715775, Iran

Full list of author information is available at the end of the article
}

is accomplished. Mixing components is required in selfcured composites to begin polymerization. This may cause air-bubble porosity in the material. For light-cured resins, a hand held curing light that emits specific wavelengths works as the polymerization initiator.

In comparison with a common alternative restoration material, amalgam, synthetic resins exhibit superior aesthetics. High demand for tooth colored restorations in anterior and posterior teeth has triggered investigations of composite resin characteristics to improve poor outcomes 
such as microleakage which affects durability of tooth colored restorations, leading to restoration failure as well as post-operative sensitivity [1].

Thorough curing of composite resins is critical since it has a direct relation to the physical and mechanical characteristics of the resin composite. A main issue with composite resins is insufficient polymerization after curing. Insufficient polymerization due to poor curing, leads to increased water absorption, and compromised mechanical characteristics including less hardness, more erosion, micro-leakage, secondary caries, and as a consequence, failure of the composite filling [2,3]. One way to combat these problems is to select the best light curing system.

For many years, it has been common to use halogen light as the conventional curing mode [4]. Recently LED devices have come in to the dental market. Use of these devices is increasing due to durability of the device, no need to replace the filter and bulb, lower heat generation, and no cooling down [5]. In LED devices, there are three different modes for polymerizing and curing composite resins; ramped, pulse-delay, and conventional modes. Some researchers believe that there is no significant difference in restoration quality between the conventional curing technique with halogen devices, and LED curing, in terms of micro-leakage [6,7]. Other researchers have postulated that LED methods may not yield better results in reducing microleakage, in comparison to the conventional QTH curing method [8,9].

Considering the increased use of LED devices, and also considering contradictions in previous research results, the current study, comparing the effects of three different

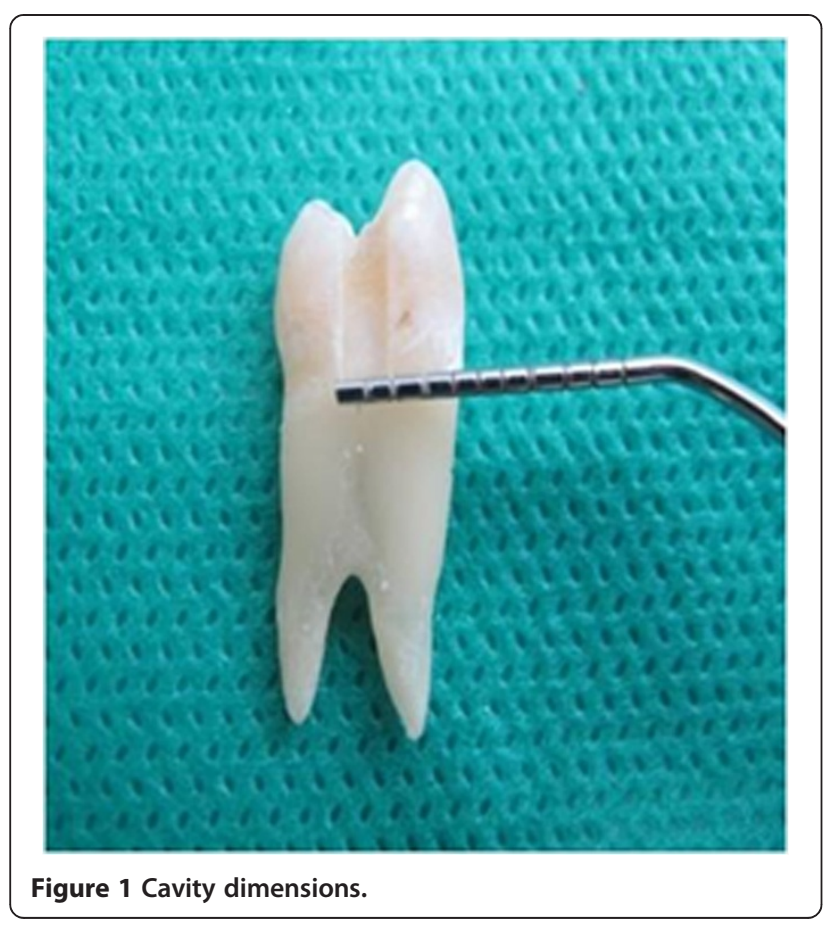

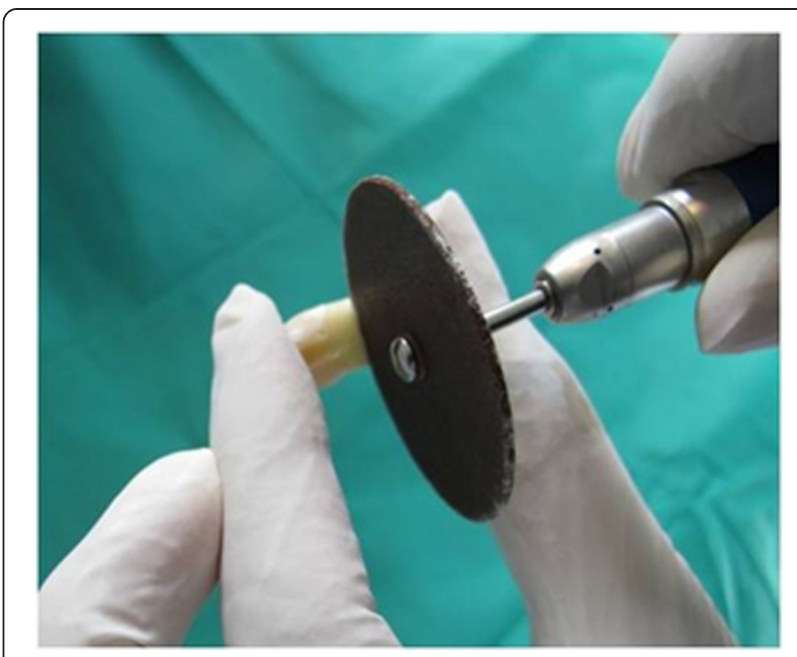

Figure 2 Cutting the root tip.

methods of LED composite resin curing with conventional QTH curing is timely. This will clarify evidence based outcomes to help dental practitioners choose the most valid and reliable method of light curing. In the current study our main question is whether replacing a QTH curing unit with a LED one, and applying one of these different methods of LED curing will reduce, increase, or cause no significant effect in terms of micro-leakage in enamel or in dentin in comparison to QTH composite resin curing. And we have tested the hypothesis of "micro-leakage of class II dental composite restorations with QTH dental curing light is higher than LED curing produces".

\section{Methods}

This in vitro study is a double blind, imbalanced randomized (3:1), cross sectional study conducted in Iran.

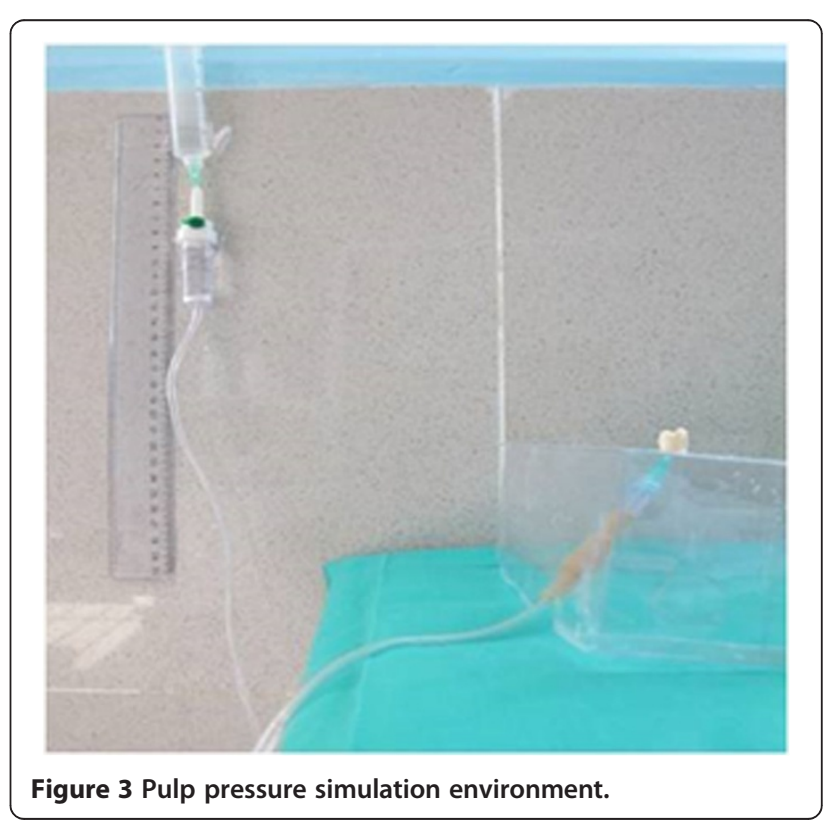




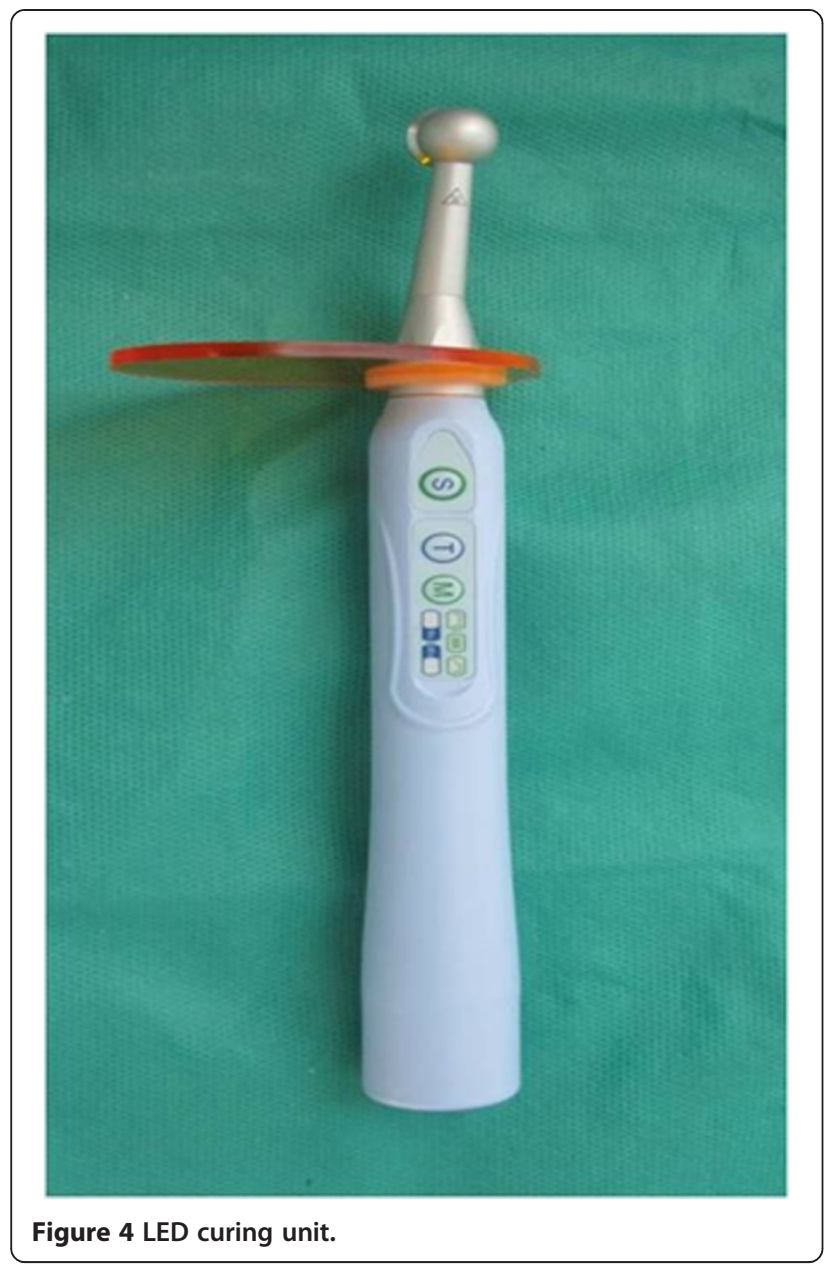

In this experimental in vitro study, we used 100 intact human premolars, free of caries and fracture lines, which have been extracted already for orthodontic treatment, and we did not extract any tooth in order to perform this study. The study was carried out in the restorative laboratory of Ahvaz Jundishapur School of Dentistry, Ahvaz, Iran, from June 2011 to July 2012. This study was approved by the Research Ethics Committee of

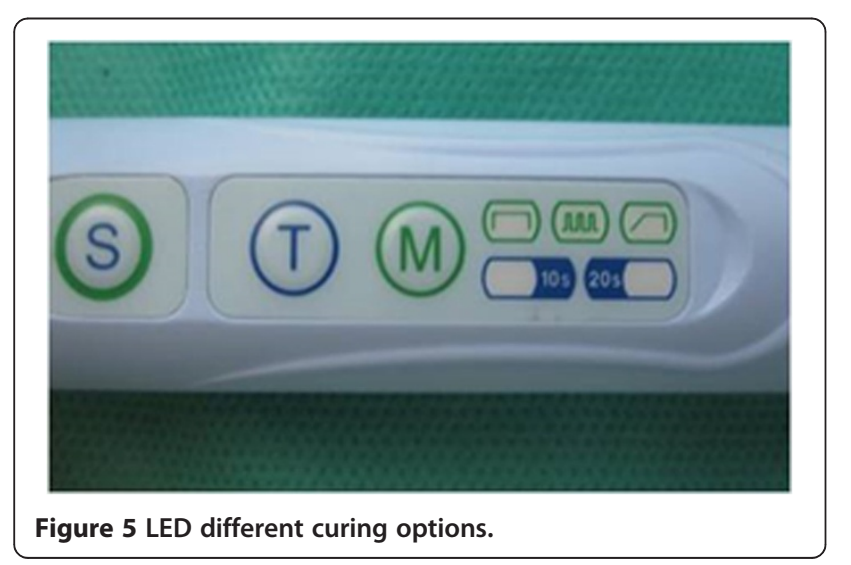

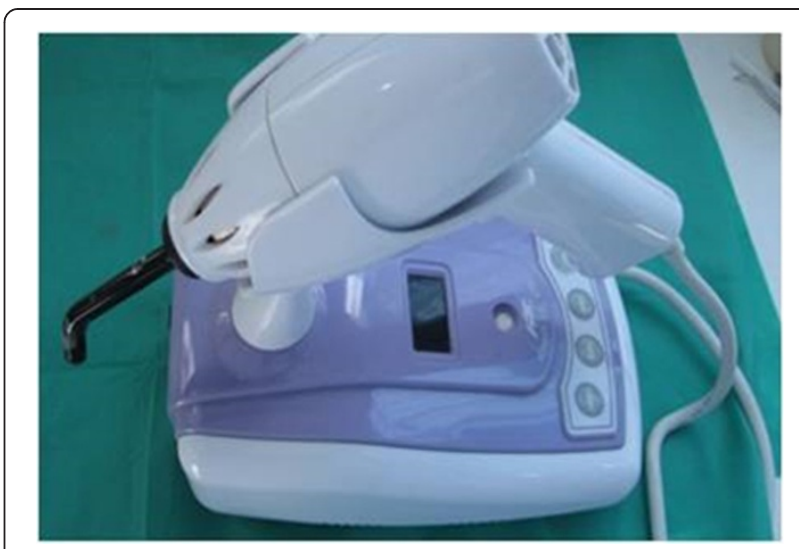

Figure 6 QTH curing unit.

Ahvaz Jundishapur School of Dentitry (U-90233). Any experimental research that is reported in this manuscript, have been performed with the approval of an appropriate ethics committee.

The teeth were rinsed with a soft brush and water, and maintained in normal saline solution. A restorative specialist prepared similar size class II cavities with the occluso-gingival and mesio-distal dimensions of $2 \mathrm{~mm}$ and bucco-lingual dimension of $1.5 \mathrm{~mm}$ (Figure 1), all with the same high speed handpiece (PAXTUB2, NSK, Shinagawa, Tokyo, Japan), diamond bur (835KR010, D\&Z, Goerzallee, Berlin, Germany), and cooling system for air and water, to avoid confounding factors. The gingival margin was prepared $1 \mathrm{~mm}$ lower than CEJ. The apical half of each root was separated by a diamond disk (Figure 2). The pulp was exposed, and pulp tissue removed by a small barbed broached file. The pulp canal was irrigated with a $2.5 \%$ sodium hypochlorite solution for 30 seconds and the tooth was kept in water for 30 minutes. All coronal

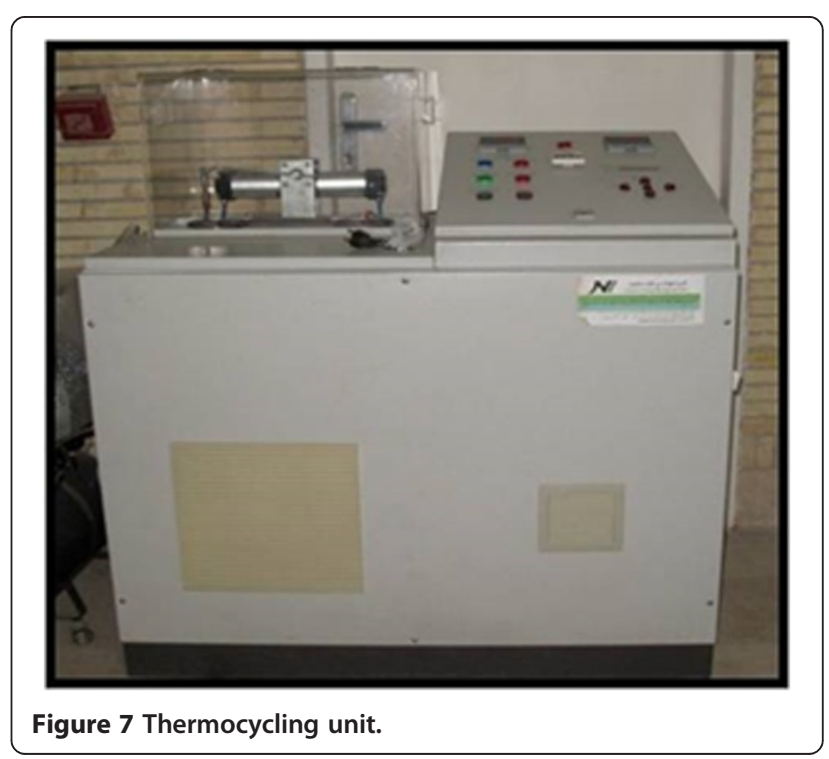




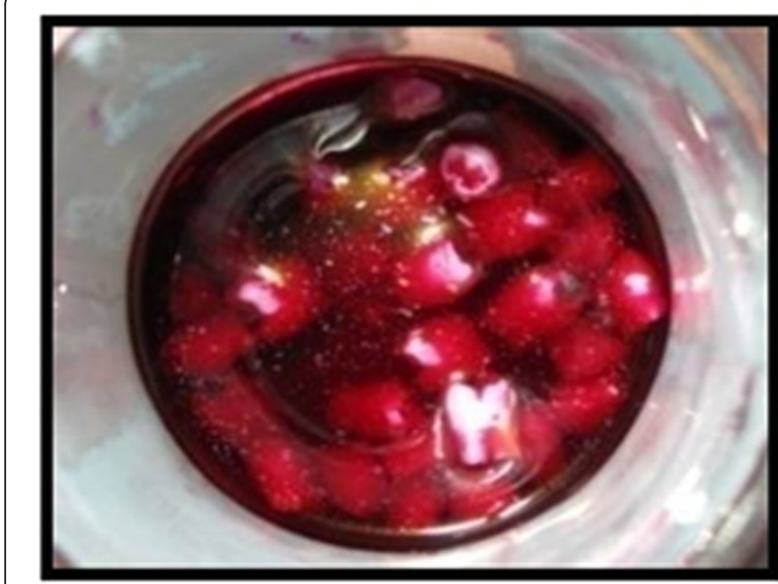

Figure 8 All teeth were immersed in $2 \%$ basic fuchsine for 24 hours.

segments were attached to a plate, using sticky wax. An 18 gauge stainless steel tube was inserted into the center of this plate. The entry of the stainless steel tube to the pulp chamber was sealed with sticky wax. The tube was connected to a $10 \mathrm{~cm}$ plastic syringe through a plastic pipe. To simulate the vital tooth pulp pressure of 34$40 \mathrm{~cm} \mathrm{H}_{2} \mathrm{O}$ (Figure 3 ) in all samples, a syringe reservoir, filled with distilled water, was placed $25 \mathrm{~cm}$ above the tooth surface to create the pressure of $35 \mathrm{~cm} \mathrm{H}_{2} \mathrm{O}$ at the dentin surface. The same pressure was used for all cases.

While all teeth were connected to the syringes for pulp pressure simulation, the cavity preparations were etched for 15 seconds with 35\% phosphoric acid gel (Ultra-Etch, Ultradent, South Jordan, UT, USA) and rinsed for $10 \mathrm{sec}-$ onds. After applying a single bond (3M ESPE, St ovePaul, MN, USA), the cavities were filled with the micro hybrid composite (A1 colour) Valux (3M ESPE, St Paul, MN, USA). Afterward, the entire surfaces of the fillings

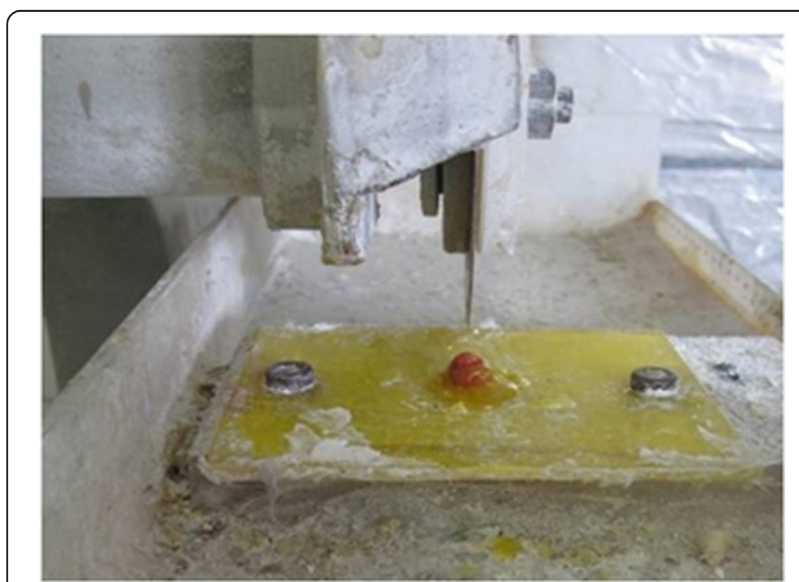

Figure 9 Section unit diamond disk.

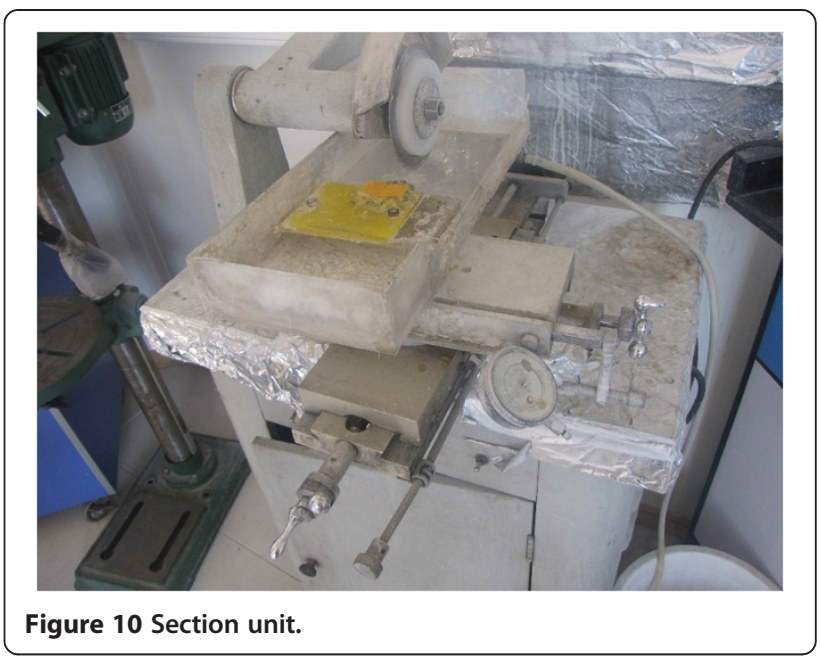

were polished with Sof-Lex ${ }^{\mathrm{TM}}$ (3M ESPE, St. Paul, MN, USA) finishing disks.

Teeth were randomly divided into 4 groups of 25 (three experimental groups and one control group). Experimental groups were exposed for 20 seconds to one of the three modes conventional, pulse-delay, ramped) of LED light (Bonart, ART-L3, Xinzhuang District, New Taipei City, Taiwan) "(Figures 4 and 5)". The control group was cured for 20 seconds by QTH (Figure 6, Bonart, ART-L2, Xinzhuang District, New Taipei City, Taiwan).

\section{The different modes of LED composite curing were applied as follows \\ Conventional}

Irradiation started at the highest intensity $(400 \mathrm{mw} / \mathrm{cm} 2)$, continues without alteration in intensity to the end curing time. The output radiation wavelength remained 450$470 \mathrm{~nm}$.

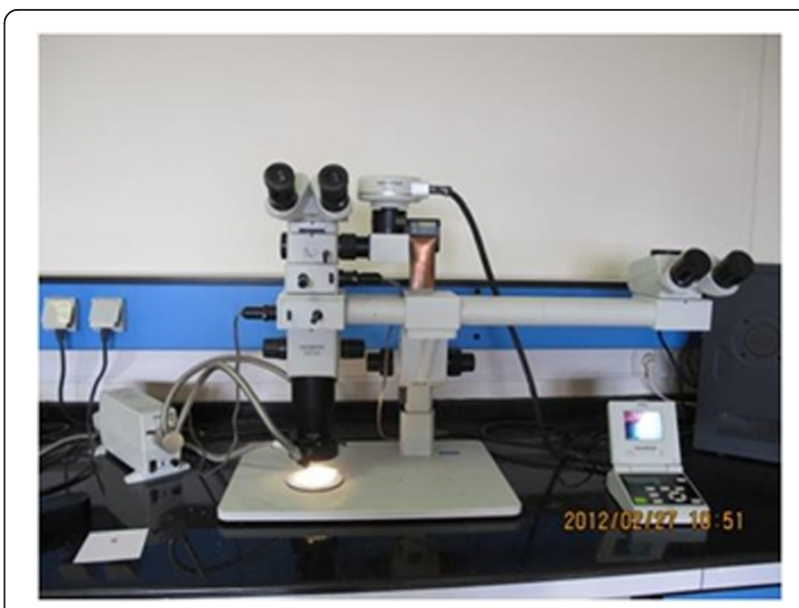

Figure 11 Stereo-microscope unit. 


\section{Ramped}

Irradiation was initiated at $100(400 \mathrm{mw} / \mathrm{cm} 2)$ increasing to maximum intensity which was maintained to the end of the curing time.

\section{Pulse}

Irradiation started with $400(400 \mathrm{mw} / \mathrm{cm} 2)$ for 1 second, then 0.2 delay. This output was repeated to the end curing time.

\section{QTH curing mode was applied as follows}

The output radiation intensity of the QTH resin composite curing method was between $400-500 \mathrm{mw} / \mathrm{cm} 2$.

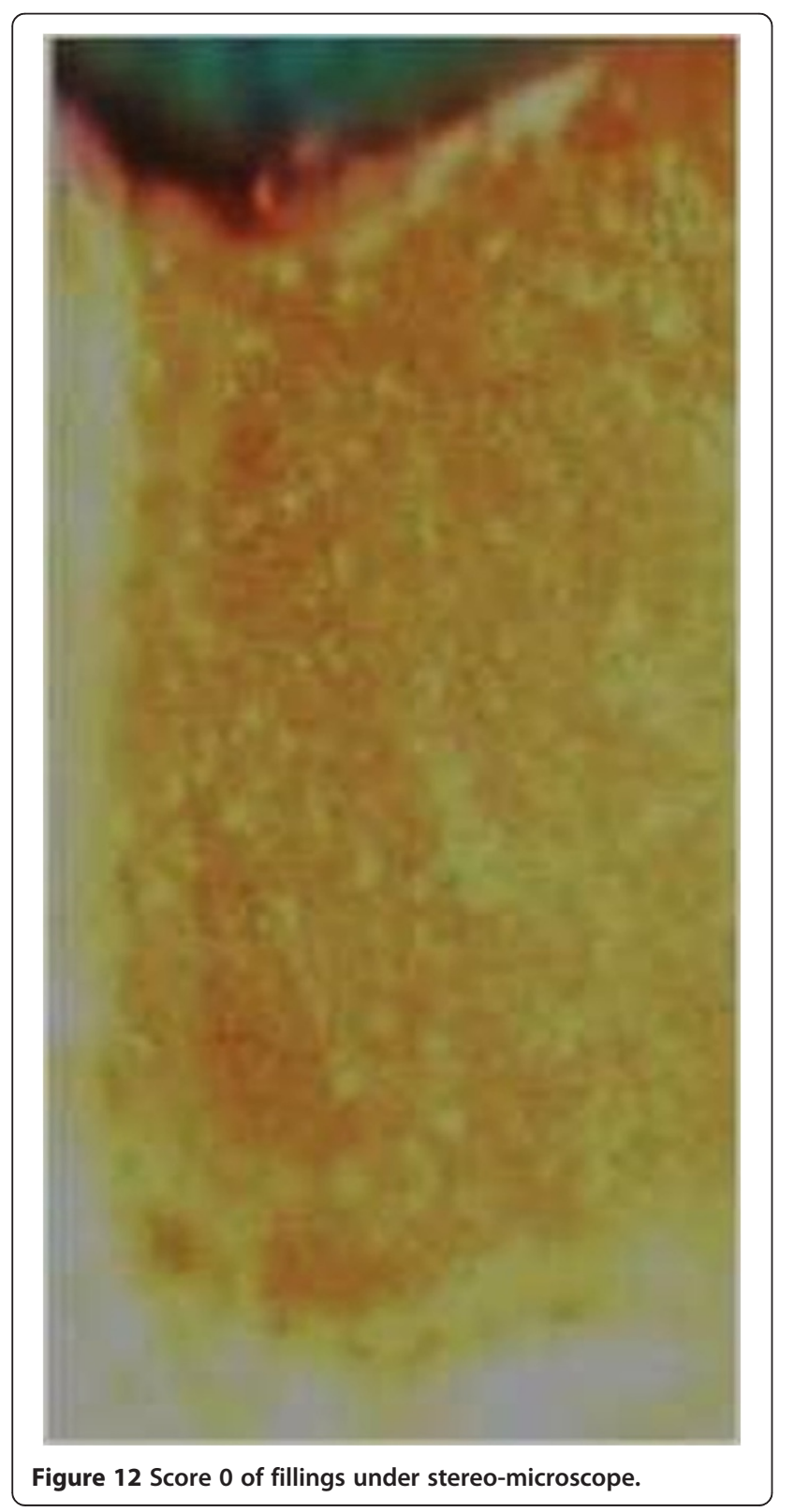

All surfaces of the teeth were sealed up to a $1 \mathrm{~mm}$ border around each preparation margin with nail polish. When the nail polish dried, the root ends were sealed by the sticky wax. Then the teeth were thermo-cycled (Figure 7, Thermo-cycling Machine, 86-1, Naftmachine Group Engineering, Tehran, Iran) for 1000 cycles between $5^{\circ} \mathrm{C}$ and $55^{\circ} \mathrm{C}$, using a dwell time of 5 seconds. All teeth were immersed in 2\% fuchsin basic dye (Figure 8, Certistain Fuchsin, CI 42510, Merck, KGaA, Darmstadt, Germany) for 24 hours, and then were rinsed under water.

A longitudinal section was made; Figures 9 and 10 by sectioning machine (Gilling-Hamco, Thin Sectioning Machine, Hamco Machines, Inc, Rochester, New York, USA) with a diamond disk (FEJ, Germany) through each filling in a mesio-distal plane, then viewed under a stereomicroscope unit (Figure 11, Olympus, SZX9, Tokyo, Japan) at $\times 40$ magnification; (Figures 12, 13, 14, 15 and 16).

All materials which have been used in this study are shown in the first three tables by their brand name, model, name of the company, city, province, and country. Microleakage has been assessed based on dye penetration, through a common scoring method of 0-4 per the following criteria:

1: Dye penetration less than half the length of the gingival floor,

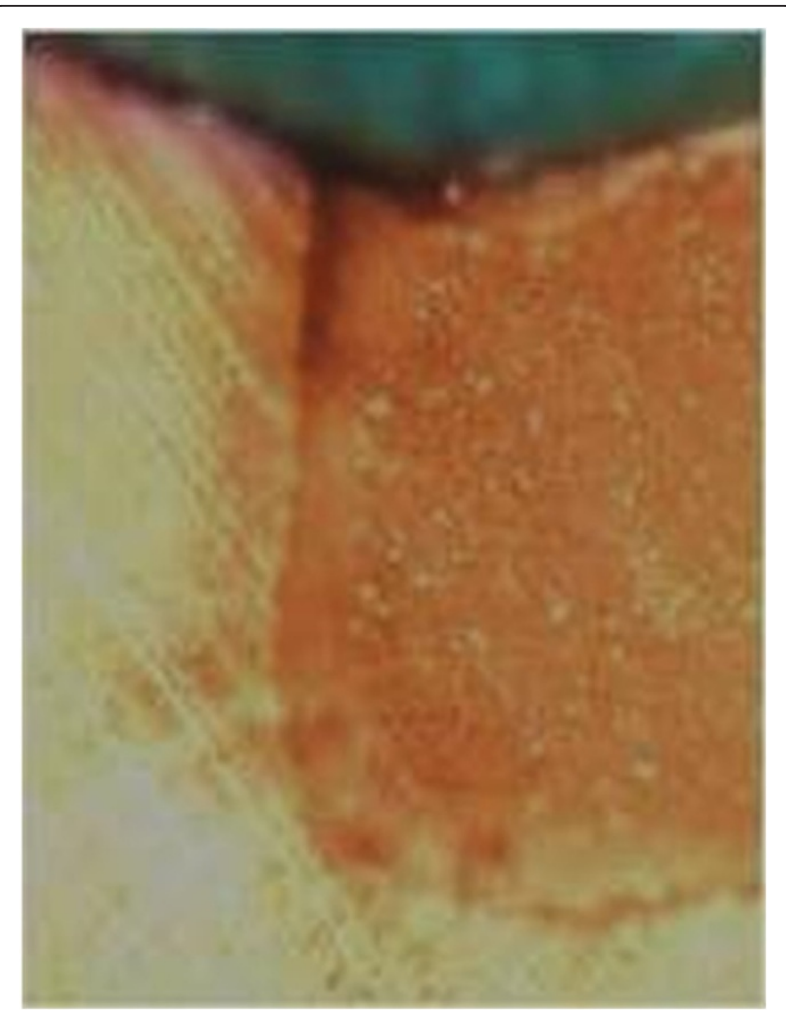

Figure 13 Score 1 of fillings under stereo-microscope. 


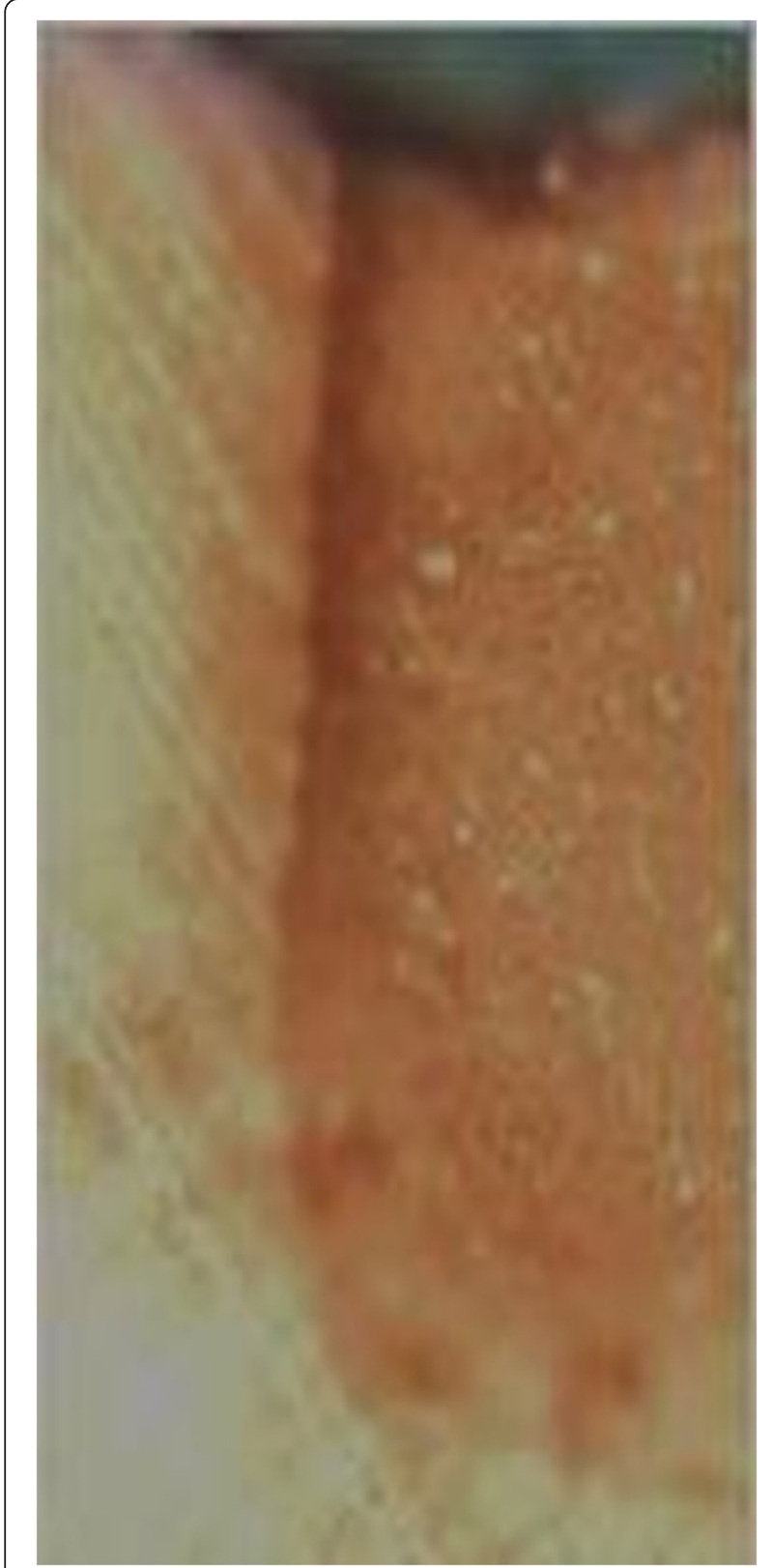

Figure 14 Score 2 of fillings under stereo-microscope.

2: Dye penetration greater than half, up to the whole length of the gingival floor,

3: Dye penetration the whole length of the gingival floor plus up to half of the axial wall.

4: Dye penetration the whole length of the gingival floor plus greater than half the axial wall and existence of lateral microleakage at dentin tubules.

A successful reading displayed evidence of one of the designated categories, an unsuccessful test was not readable.

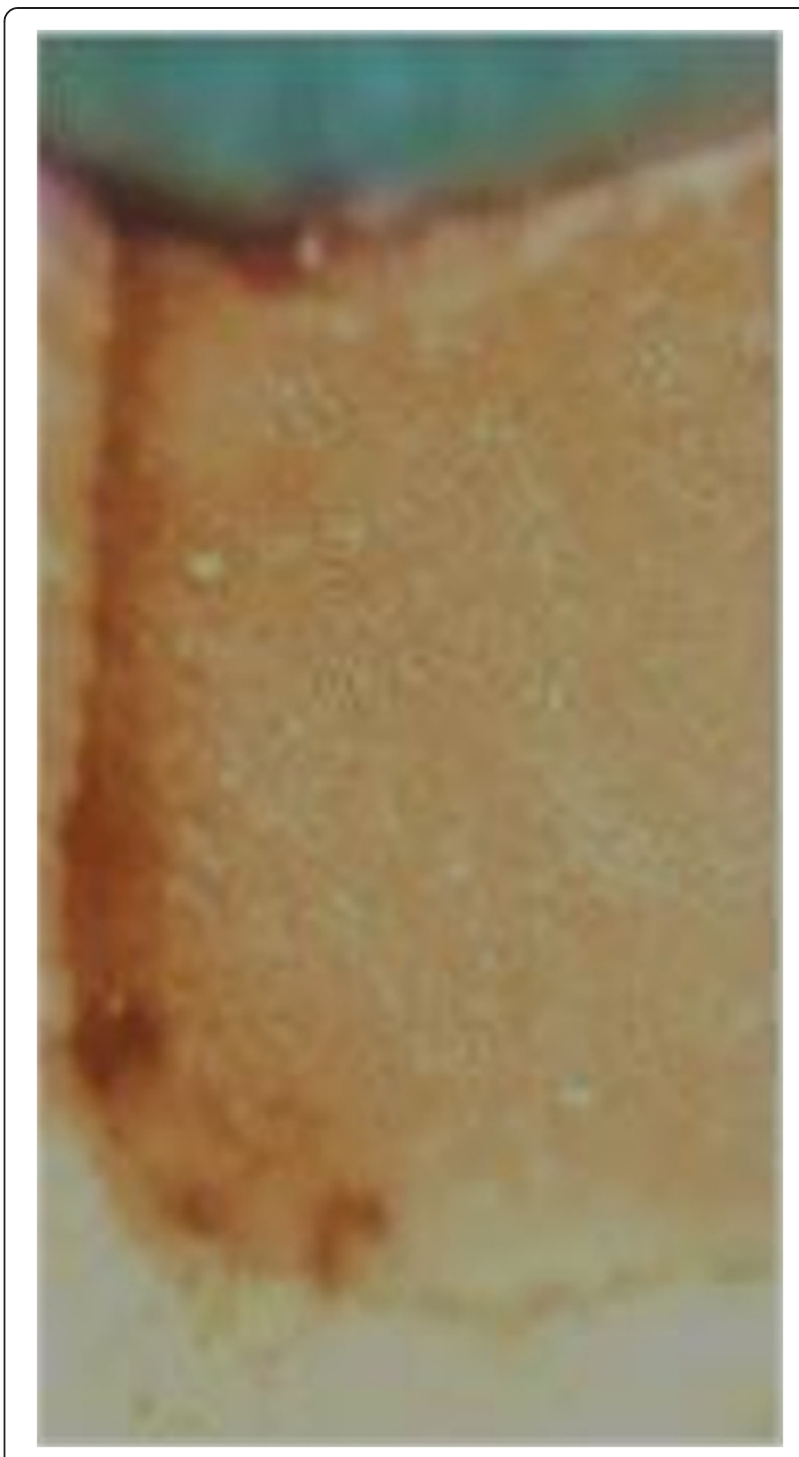

Figure 15 Score 3 of fillings under stereo-microscope.

One hundred intact human premolar teeth were collected, stored, disinfected and handled per the guidelines of OSHA and the CDC. Sample size calculations were performed based on standard deviation and statistical error estimates. For assigning the teeth into four groups, a computer-generated list of random numbers was used. Researchers (both senior and junior) were blind to which teeth were randomly divided into three experimental groups and one control group. The data were analyzed using the Chi- square test.

\section{Results}

The result of this study provides useful clinical information for effective selection of curing lights and curing modes to reduce microleakage in composite resin dental restorations. 


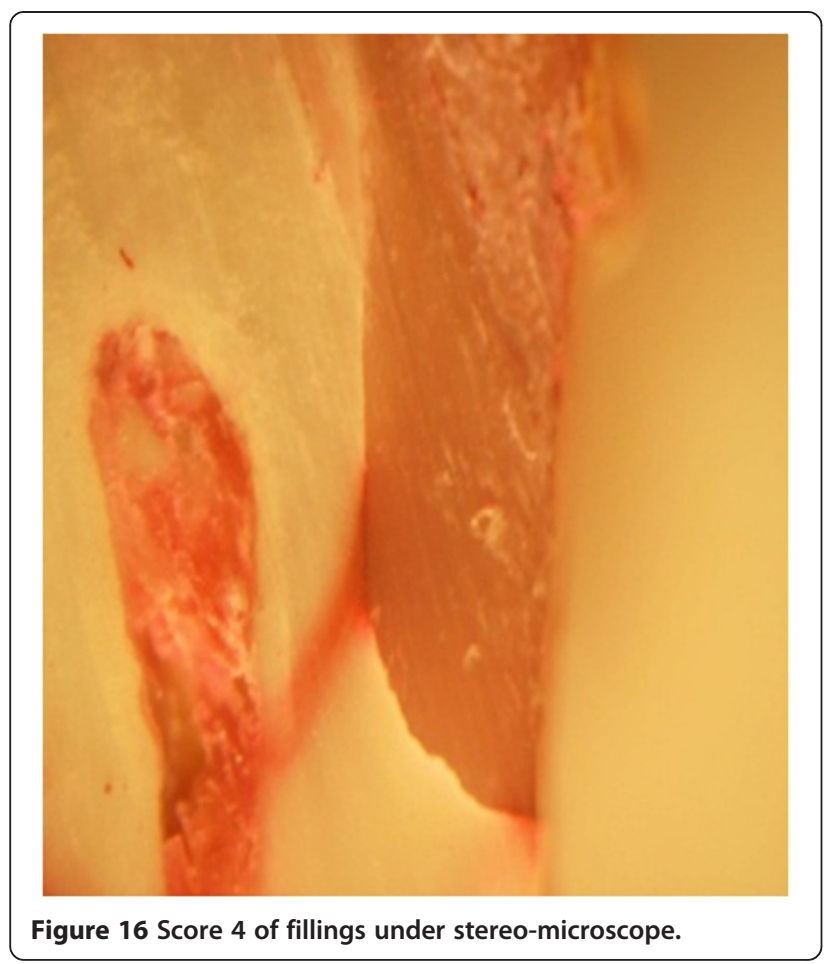

\section{Enamel}

Most score 0 was reported for specimens in all groups. The Chi-square test, $(p=0.06 \%(p>0.05 \%)$ achieved), shows no statistical difference among the four groups (Table 1).

\section{Dentin}

Most score 4 was reported for specimens of QTH and conventional cure LED groups.

The highest numbers of score 3 went to LED pulsedelay $=56 \%$ and LED ramped $=52 \%$ specimens. Since the result of the Chi-square test is $p=0 \%(p<0.05 \%)$, there is a statistical significant difference among the groups. Therefore the binary comparisons of the groups were studied (Table 2).

Based on the Chi-square tests, the binary comparisons of all pairs of groups were statistically significant, except for the comparison of LED (pulse delay) vs. LED (ramped) groups.

\section{Discussion}

Because enamel structure is homogenous, adherence to the enamel is expected to be dependable and readily achievable. However, acceptable adherence to the dentin is more complicated, due to factors including being nonuniform, movement of dentin liquid toward the external surface of dentin, and lesser percentage of organic compounds [10]. If the shrinkage force of polymerization is higher than the initial adherence strength of the composite to the dentin, a gap will occur. This phenomena happens more often in root surfaces, as opposed to the crowns of teeth [1]. In this study, most samples did not show microleakage at the enamel margins, which was in agreement with other studies [10-15].

Based upon this study, microleakage in dentin using QTH and LED (conventional curing mode), were often scored 4, while LED (ramped and pulse-delay modes) were scored 3, indicating less microleakage. This study suggests that slow-start light irradiation improves seal and marginal integrity; however unmodulated intense irradiation compromises this goal, correlating with previous research results $[11,12,16]$.

According to the findings of this research, the microleakage detected in QTH light cured samples, is significantly higher than in samples cured by three modes of LED. Potentially this may be due to the coordination of LED optical output wavelength with the comphorquinone absorption spectrum (the photo-initiator of conventional resin composites). The amount of microleakage in the modes of ramped and pulse-delay curing by LED device was similar. As described earlier, the amount of microleakage appeared to be associated with the intensity of the LED light source. Unmodulated light intensity appears to cause an increase in polymerization shrinkage and therefore more microleakage, in this study.

LED light cure releases well-defined stimulated electrons. The output spectrum of LED is coordinated with the absorption spectrum of comphorquinone photoinitiator (450-500 nm), therefore it does not need any

Table 1 Microleakage in enamel

\begin{tabular}{|c|c|c|c|c|c|}
\hline \multirow[t]{2}{*}{ Total } & \multicolumn{2}{|c|}{1} & \multicolumn{2}{|c|}{0} & \\
\hline & Percentage & Numbers & Percentage & Numbers & Grc \\
\hline 25 & 32 & 8 & 68 & 17 & QTH \\
\hline 25 & 20 & 5 & 80 & 20 & LED conventional \\
\hline 25 & 12 & 3 & 88 & 22 & LED pulse-delay \\
\hline 25 & 24 & 6 & 76 & 19 & LED ramped \\
\hline \multicolumn{6}{|c|}{ P-value $=0.06$} \\
\hline
\end{tabular}


Table 2 Microleakage in Dentin

\begin{tabular}{|c|c|c|c|c|c|c|c|c|c|c|}
\hline \multirow{2}{*}{$\begin{array}{l}\text { Total numbers of } \\
\text { successful tests } \\
\text { (excluding } \\
\text { non-readable) }\end{array}$} & \multirow{2}{*}{$\begin{array}{c}\text { Total } \\
\text { number } \\
\text { of } \\
\text { samples }\end{array}$} & \multicolumn{2}{|r|}{4} & \multicolumn{2}{|r|}{3} & \multicolumn{2}{|r|}{2} & \multicolumn{2}{|c|}{1} & \multirow{2}{*}{$\begin{array}{l}\text { Score } \\
\text { Group }\end{array}$} \\
\hline & & Numbers & Percentage & Numbers & Percentage & Numbers & Percentage & Numbers & Percentage & \\
\hline 24 & 25 & 19 & 76 & 1 & 4 & 3 & 12 & 1 & 4 & QTH \\
\hline 24 & 25 & 23 & 92 & 0 & 0 & 1 & 4 & 0 & 0 & $\begin{array}{c}\text { LED } \\
\text { conventional }\end{array}$ \\
\hline 25 & 25 & 0 & 0 & 14 & 56 & 11 & 44 & 0 & 0 & LED pulse-delay \\
\hline 24 & 25 & 2 & 8 & 13 & 52 & 9 & 36 & 0 & 0 & LED ramped \\
\hline \multicolumn{11}{|c|}{ P-value $=0.00$} \\
\hline
\end{tabular}

filter. It has been postulated that two possible methods to reduce polymerization shrinkage stress reduction are soft-start curing and pulse delay, which have been confirmed in this study. However some studies indicate that the amount of dentinal microleakage in both LED light cure device, and QTH, is similar. It may be due to the different intensity of various applied light curing units [1,13,14,17-19].

Bouschlicher et al. [19], reported similar evidence of polymerization shrinkage comparing a stepped light curing method and unmodulated QTH curing, which contradicts our results. They applied $100 \mathrm{mw} / \mathrm{cm}^{2}$ initial light intensity for 10 seconds and $800 \mathrm{mw} / \mathrm{cm}^{2}$ final intensity for 30 seconds. Their higher final intensity was higher than our method, which may be a reasonable justification for the higher shrinkage and microleakage.

In one investigation, microleakage between LED and QTH cured composite resin samples after 3 months storage time was not statistically significant, whereas in a 24 hours period there was meaningful leakage noted [12]. Water absorption of composite is inevitable resulting in hygroscopic expansion. Volumetric expansion compensates for the initial shrinkage and temporarily reduces microleakage. This expansion occurs in first few days. After one week, when the resin composite is saturated, the compensating effect stops and microleakage increases due to resin composite solubility [2].

Hassani Tabatabaei et al. [10], in opposition to the results of our study, reported that in dentinal walls, microleakage produced by LED soft-start curing and LED pulse-delay methods is higher than in the QTH conventional curing method (Astralis 7 Ivoclar Vivadent

Table 3 Conclusion table

\begin{tabular}{ccccc}
\hline & QTH & $\begin{array}{c}\text { LED } \\
\text { (Conventional) }\end{array}$ & $\begin{array}{c}\text { LED } \\
\text { (pulse delay) }\end{array}$ & $\begin{array}{c}\text { LED } \\
\text { (ramped) }\end{array}$ \\
\hline QTH & - & $\mathrm{S}$ & $\mathrm{S}$ & $\mathrm{S}$ \\
LED (Conventional) & $\mathrm{S}$ & - & $\mathrm{S}$ & $\mathrm{S}$ \\
LED (pulse delay) & $\mathrm{S}$ & $\mathrm{S}$ & - & $\mathrm{NS}$ \\
LED (ramped) & $\mathrm{S}$ & $\mathrm{S}$ & $\mathrm{NS}$ & - \\
\hline
\end{tabular}

QTH). Their findings are based upon a different composite resin choice, and a higher light intensity LED unit; comparison with our findings is difficult.

Frield K. et al. [20] and Hofmann N. et al. [21] have reported results which conflict with the present study results. They have used higher light intensity (more than $600 \mathrm{mw} / \mathrm{cm}^{2}$ ) in their research, while in our study, the light intensity was gradually increased and reached up to $400 \mathrm{mw} / \mathrm{cm}^{2}$ at the peak. Our results suggest the advantages of lower initial polymerization: Higher elasticity, and lower tension in the cured material produced by the soft-start method may be reduced if the final exposure is too high, causing an increase in total shrinkage.

\section{Conclusions}

Results of this study indicate that there is no significant difference among various methods of LED curing, and QTH curing, at the enamel margins reflected by score 0 for most specimens. However, at dentin margins, there are significant differences.

Both LED and QTH eliminate microleakage almost completely at the enamel margin; however none of them can absolutely overcome the dentinal microleakage. Between two light sources (LED and QTH), LED is observed to be more effective in all different modes. LED composite resin curing offers better penetration depth, lower heat production, and repeatable clinical results in comparison to QTH light curing. Delay-pulse and ramped LED curing reduced dentinal microleakage in a statistically significant manner compared to unmodulated LED and QTH curing lights (Table 3).

\section{Competing interests}

The authors declare that they have no competing interests.

\section{Authors' contributions}

FZ designed the study, carried out cavity preparations, and performed the statistical analysis. LGH conceived the study and helped to draft the manuscript. SS performed the laboratory assays and helped to draft the manuscript. VF performed the final statistics and rewrote the final manuscript, AD made substantial contributions to conception, design, acquisition of data, the analysis and interpretation of the data, and was involved in drafting and reviewing the manuscript for important intellectual 
content. EG helped to collect the data. NZ helped to collect the data. All authors contributed to the study and confirmed the final version of the submitted manuscript. All authors read and approved the final manuscript.

\section{Authors' information}

FZ is the dean of Ahvaz Jundishapur Dental School and head of restorative and operative department.

\section{Acknowledgements}

Authors would like to give their deepest appreciation to Dr. Virginia Freckelton, Assistant Professor of the Dental Practice Department of Arthur A. Dugoni School of Dentistry, who has reviewed this article precisely and kindly edited it finally.

Also we would like to express the deepest appreciation to our study leader, Dr. Faramarz Zakavi and Dr. Leila Golpasand Hagh, for their guidance and inspiration. They continually conveyed a spirit of adventure in regard to research, and an excitement in regard to teaching. Without their guidance and persistent help, our ongoing projects in the Restorative Department of Ahvaz Jondishapor School of Dentistry would not move forward to establish and improve preventive dentistry and further the comfort and care of the patients.

\section{Author details}

${ }^{1}$ Department of Operative and Esthetic Dentistry, Ahvaz Jundishapur Dental School, Ahvaz Jundishapur University of Medical Sciences, Ahvaz 6135715775, Iran. ${ }^{2}$ Department of Periodontology, Ahvaz Jundishapur Dental School, Ahvaz 6135715775, Iran. ${ }^{3}$ Department of Operative and Esthetic Dentistry, Urmia Dental School, Urmia 5714783734, Iran. ${ }^{4}$ Department of Dental Practice, Oral Medicine Clinic, University of the Pacific Arthur A. Dugoni School of Dentistry, San Francisco, CA 94103, USA.

Received: 30 January 2014 Accepted: 23 June 2014

Published: 3 July 2014

\section{References}

1. He Z, Shimada Y, Taqami J: The effects of cavity size and incremental technique on micro-tensile bond strength of resin composite in class I cavities. Dent Mater 2007, 23:533-538.

2. Craig G, Robert M: Dental material restorative. 11th edition. USA: Mosby; 2006:187,144

3. Bala O, Uctasli M, Tuz MB: Hardness of different resin-based composites cured by halogen or light emitting diod. J Oper Dent 2005, 30:69-74

4. Asmussen E, Peutz A: Light emitting diode curing: influence on selected properties resin composite. Quintessence Int J Oper Dent 2003, 34:5-7.

5. Dunn W, Bush A: A comparison of polymerization by light-emitting diode and halogen-based light units. J Am Dent Assoc 2002, 133:335-341.

6. Oxman J, Paton B, Felix C: Effect of Wave Length on Resin Hardness \& Light Transmission. 8th edition. USA: Mosby; 2004:117.

7. Ramp L, Broome J, Ramp M: Hardness and wear resistance of two resin composites cured with equivalent radiant exposure from a low irradiance LED and QTH light-curing units. Am J Dent 2006, 19:6-9.

8. Yazici A, Kugel G, Gul G: The Knoop hardness of a composite resin polymerized with different curing lights and different modes. J Contemp Dent Pract 2007, 8:52-59.

9. Toroghi A: Evaluation of Light Cure Unit on Micro Hardness of Composite Z250. Tehran, Iran: Azad Eslami Tehran University of Medical Sciences 1386; 2007. Dissertation.

10. Hassani Tabatabaie M, Ataie M, Safar Charati H: Effect of different curing methods and microleakage and degree of conversion of composite resin restorations. J Dent Tums 2003, 16:18-27.

11. Oberholzer TG, Kidd M: Effect of LED curing on microleakage and microhardness of class $\mathrm{V}$ resin-base composite restorations. J Oper Dent 2004, 54:15-20.

12. Theunis G, Oberholzer: Effect of LED curing on the microleakage, shear bond strength and surface hardness of a resin - based composite restoration. J Dent Mat 2005, 26:3981-3986.

13. Attar N, Korkmaz Y: Effect of two light-emitting diode (LED) and one halogen curing light on the micrleakage of class $\mathrm{V}$ flowable composite restorations. J Contemp Dent Pract 2007, 1:80-88.
14. Nemati anaraki S, Haji G: The effect of different light curing on microleakage of composite restorations. Shiraz uni Dent J 2010, 10:316-321.

15. Jain $P$, Pershing A: Depth of cure and microleakage with high-intensity and ramped resin based composite curing lights. J Am Dent Assoc 2003, 134:1215-1223.

16. Ahmed $H$, Salah $H$ : Evaluation of the microleakage, curing depth and microhardness of composite resins using a Halogen and LED. J Dent 2009, 55:2555

17. Fleming GJ, Khan S, Afzal O, Palin WM, Burke FJ: Investigation of polymerization shrinkage strain, associated cuspal movement and microleakage of MOD cavities restored incrementally with resin-based composite using an LED light curing unit. J Dent 2007, 35:97-103.

18. Queiroz RS, Bandeca MC, Calixto LR, Saade EG, Nadalin MR, Andrade MF, Porto-Neto ST: Effects of light curing units on microleakage under dental composite resins. Laser Phys 2009, 19:1909-1911.

19. Bouschlicher MR, Rueggeberg FA, Boyer DB: Effect of stepped light intensity on polymerization force and conversion in a photo activated composite. J Esthet Dent 2000, 12:23-32.

20. Friedl K, Schmalz G, Hiller K, Markl A: Marginal adaptation of class V restorations with and without soft start polymerization. Oper Dent 2000, 25:26-32.

21. Hofmann N, Sibrecht C, Hugo B, Kleiber B: Influence of curing methods and materials on the marginal seal of class $\mathrm{V}$ composite restorations in vitro. Oper Dent 2003, 28:160-167.

\section{doi:10.1186/1756-0500-7-416}

Cite this article as: Zakavi et al:: Evaluation of microleakage of class II dental composite resin restorations cured with LED or QTH dental curing light; Blind, Cluster Randomized, In vitro cross sectional study. BMC Research Notes 2014 7:416.

\section{Submit your next manuscript to BioMed Central and take full advantage of:}

- Convenient online submission

- Thorough peer review

- No space constraints or color figure charges

- Immediate publication on acceptance

- Inclusion in PubMed, CAS, Scopus and Google Scholar

- Research which is freely available for redistribution

Submit your manuscript at www.biomedcentral.com/submit
C BioMed Central 